\title{
Fuel retention in JET ITER-Like Wall from post-mortem analysis
}

\author{
K. Heinola ${ }^{1,2}$, A. Widdowson ${ }^{2}$, J. Likonen ${ }^{3}$, E. Alves ${ }^{4}$, A. Baron-Wiechec ${ }^{2}$, \\ S. Brezinsek ${ }^{5}$, N. Catarino ${ }^{4}$, P. Coad $^{2}$, S. Koivuranta ${ }^{3}$, G. F. \\ Matthews $^{2}$, M. Mayer ${ }^{6}$, P. Petterson ${ }^{7}$ and JET-EFDA Contributors ${ }^{\dagger}$ \\ JET-EFDA, Culham Science Centre, OX14 3DB, Abingdon, UK \\ ${ }^{1}$ Association EURATOM-TEKES, University of Helsinki, PO Box 64, 00560 Helsinki, Finland \\ ${ }^{2}$ EURATOM/CCFE Fusion Association, \\ Culham Science Centre, Abingdon, OX14 3DB, UK \\ ${ }^{3}$ Association EURATOM-TEKES, VTT, \\ PO Box 1000, 02044 VTT, Espoo, Finland \\ ${ }^{4}$ Instituto Superior Tecnico, Instituto de Plasmas e Fusao Nuclear, \\ Universidade de Lisboa, 1049-001 Lisboa, Portugal \\ ${ }^{5}$ Forschungszentrum Julich GmbH, EURATOM Association, D-52425, Julich, Germany \\ ${ }^{6}$ Max-Planck Institut fur Plasmaphysik, \\ EURATOM Association, D-85748, Garching, Germany and \\ ${ }^{7}$ Royal Institute of Technology, Association EURATOM-VR, SE-10044, Stockholm, Sweden
}

\begin{abstract}
Selected Ion Beam Analysis techniques applicable for detecting deuterium and heavier impurities have been used in the post-mortem analyses of tiles removed after JET ITER-Like Wall campaign. Over half of the retained fuel was measured from the divertor region. Highest figures for fuel retention were obtained from regions with thickest deposited layers, i.e. in the inner divertor on top of Tile 1 and on High Field Gap Closure tile, which resides deep in the plasma scrape-off layer. Least retention was found in the main chamber high erosion region, i.e. in the mid-plane of Inner Wall Guard Limiter. Fuel retention values were found typically to vary with deposition layer thicknesses. The reported retention values support the observed decrease in fuel retention obtained with previous gas balance experiments.
\end{abstract}

PACS numbers: 61.72.-y 66.30.-h

\footnotetext{
† See the Appendix of F. Romanelli et al., Proceedings of the 24th IAEA Fusion Energy Conference 2012, San Diego, USA
} 


\section{INTRODUCTION}

The fuel retention in to the plasma surrounding first wall material has an essential role in economical operation of a fusion device. Moreover, the accumulation of the hazardous hydrogen isotope tritium (T) into the wall dictates the radiologically safe operation limit. Presently the maximum allowed T concentration of ITER is $1 \mathrm{~kg}$. The JET ITER-Like Wall (JET-ILW) project (see Ref.[1]) allows to assess the scale of the plasma-surface interaction effects which can take place in the course of ITER operation. In JET-ILW the vessel main chamber is made out of bulk beryllium (Be) and the divertor region comprises of bulk tungsten $(\mathrm{W})$ tiles and $\mathrm{W}$-coated carbon-fibre composite (CFC) tiles. The resulted net plasma-surface interactions, such as Be erosion and deposition and plasma fuel (deuterium, D) retention to wall tiles or deposits, can be scrutinized with post-mortem analyses performed to tiles being removed from the vessel. The removal and replacement of vessel wall tiles can be done only during dedicated shutdowns between JET experimental campaigns.

During the JET-ILW experimental campaign 2010-2012 the fuel retention was studied with a dedicated gas balance experiment [2]. In this experiment, identical plasma pulses for different plasma modes (ohmic, L-mode, type III ELMy H-mode, type I ELMy H-mode) were repeated to achieve statistically sufficient number of injected fuel particles for avoiding any historic effects caused by the JET operation. The outgassing of the retained D was monitored short term (inbetween the pulses) as well as a long-term (up to 2 days). Based on these gas balance measurements the JET-ILW shows fuel retention of $10-20$ times less than what was measured with the JET allCarbon wall. The present work continues the retention studies by analyzing the JET first wall tiles being removed from the vessel after the 2010-2012 experimental campaign. The fuel detected in these analyses show the net retention of $\mathrm{D}$ beyond the long-term outgassing, and the results map the retention distribution in the vessel.

\section{EXPERIMENTAL METHODS}

The deuterium concentrations were determined from selected JET-ILW first wall armour tiles removed from the vessel during the 2012 shutdown. Tiles comprised of representative selections from the main wall (Inner Wall Guard Limiters, IWGL and Outer Poloidal Limiters, OPL) upper region, mid-plane and lower region as well as tiles from the divertor (inner and outer divertor). 
No samples were taken from the central part of the divertor (Tile 5) at this stage. The selected tiles have special interlayer coating near the tile surface for measuring the tile erosion/deposition accurately. The main wall tiles have a Be (bulk)/Ni $(4 \mu \mathrm{m}) / \mathrm{Be}(7 \mu \mathrm{m})$ structure. The marker coated divertor tiles have a structure of CFC (bulk)/Mo $(3 \mu \mathrm{m}) / \mathrm{W}(12 \mu \mathrm{m}) / \mathrm{Mo}(4 \mu \mathrm{m}) / \mathrm{W}(4 \mu \mathrm{m})$, except Tile 3 which has the Mo layer as the plasma-facing coating.

The post-mortem analyses were carried out with ion beam analysis (IBA) methods. The Nuclear Reaction Analysis (NRA) was used for determining the deuterium concentrations via the $D\left({ }^{3} \mathrm{He}, p\right){ }^{4} \mathrm{He}$ nuclear reaction. The Elastic Backscattering (EBS) and Particle Induced X-ray Emission (PIXE) were used in detecting Be and heavier elements. The NRA, EBS and PIXE experimental setups are described more in detail in Refs. [3, 4]. In addition to NRA also the Secondary Ion Mass Spectrometry (SIMS) was used in the D analysis. Details for the SIMS setup are presented in Ref. [5].

The results from NRA, EBS and PIXE were analysed and fitted with WiNDF data furnace software package [6]. In addition to computational fitting, a set of D reference samples was prepared by implanting $60 \mathrm{keV} / \mathrm{D}_{2}$ into polycrystalline $\mathrm{W}$ (see details in Ref.[7]). The retained D in the implantation-induced defects determined with Elastic Recoil Detection Analysis (ERDA) was $3.47 \times 10^{16}$ at. $/ \mathrm{cm}^{2}$. These D implanted reference samples were used for calibrating the SIMS and NRA D results.

In addition to the IBA methods also the Thermal Desorption Spectrometry (TDS) was applied to a selected number of cored tile samples. This paper presents the first results for JET-ILW divertor samples analysed with TDS. The analysis was done in a ultra-high vacuum system with a starting pressure of $\sim 1 \times 10^{-9}$ mbar. Samples were annealed with linear ramp rates $(10 \mathrm{~K} / \mathrm{min}$ or $5 \mathrm{~K} / \mathrm{min}$ ) from room temperature (RT) up to $1000^{\circ} \mathrm{C}$. The released gases were measured with a quadrupole residual gas analyser as a function of time and annealing temperature. The TDS data was collected for mass-to-charge ratios corresponding to various molecules, e.g. $\mathrm{H}_{2}, \mathrm{HD}$, $\mathrm{D}_{2}, \mathrm{DT}, \mathrm{T}_{2}$ and $\mathrm{Be}$. The $\mathrm{D}$ signal was calibrated with a $\mathrm{D}$ reference sample described in previous paragraph.

The IBA for main wall tiles was performed using each individual tile as a sample. The divertor tiles were cored into small-sized samples (diameter $17 \mathrm{~mm}$ ), which were then analysed with SIMS and NRA. An additional set of divertor samples were cored to be used with TDS. The topmost part of these core samples were further sliced horizontally into two pieces. The resulted TDS depth profile represents depths of 0 to $1 \mathrm{~mm}$ (surface coating sample) and $1.5 \mathrm{~mm}$ to $2.5 \mathrm{~mm}$ (bulk CFC 
sample).

\section{RESULTS AND DISCUSSION}

\section{A. Main chamber \\ 1. Upper Dump Plates}

In the earlier work it was shown that the plasma-facing surfaces of the upper dump plate (DP) tiles were modified due to melting and arcing, which e.g. induced droplets of molten Be being ejected to the outer divertor $[4,8]$. These strong interactions with plasma and DP region were mostly taking place before the active use of JET's Disruption Mitigation Valve protection system.

The DP surface profiling indicated surface modifications, but no evident large scale erosion could be determined. A DP tile (identification 2B2C) surface was analysed with NRA and EBS providing information on the thickness of the residual Ni-Be coating and on fuel retention. 21 measurement points were used to cover the DP tile surface analysis. The orientation of the selected points was chosen to represent a toroidal distribution across the middle of the tile. Each individual measurement point was then analysed with WiNDF and the impurity quantities and concentration profiles were determined respectively. Due to the large-scale surface roughness on the DP tile the resulted D areal concentrations varied significantly. The mean D concentration value obtained was $(3.4 \pm 1.2) \times 10^{17}$ at. $/ \mathrm{cm}^{2}$ per one DP tile. Integrating over the whole upper DP region yields to a retention value of $1.5 \times 10^{22} \mathrm{D}$ atoms.

\section{2. $\quad$ Outer Poloidal Limiters}

Outer Poloidal Limiter (OPL) tiles used for post-mortem analysis were removed from the midplane and from the lower outer wall region (identification 4D14 and 4D3, respectively). Both of these tiles were measured with NRA, EBS and PIXE using 52 measurement points across the tile in the toroidal direction. Both of the tiles showed thinning of the Be layer in the centre part of the tile [9]. The centre region was neighboured by some deposited Be but which was lacking in the far ends of the OPL tiles. In Fig. 1 is presented the total D concentration in the toroidal direction as measured along the mid-plane OPL tile (4D14) and analysed with WiNDF. Averaging the total D concentrations yields $8.19 \times 10^{17}$ at. $/ \mathrm{cm}^{2}$. A simple D concentration assessment using the NRA 


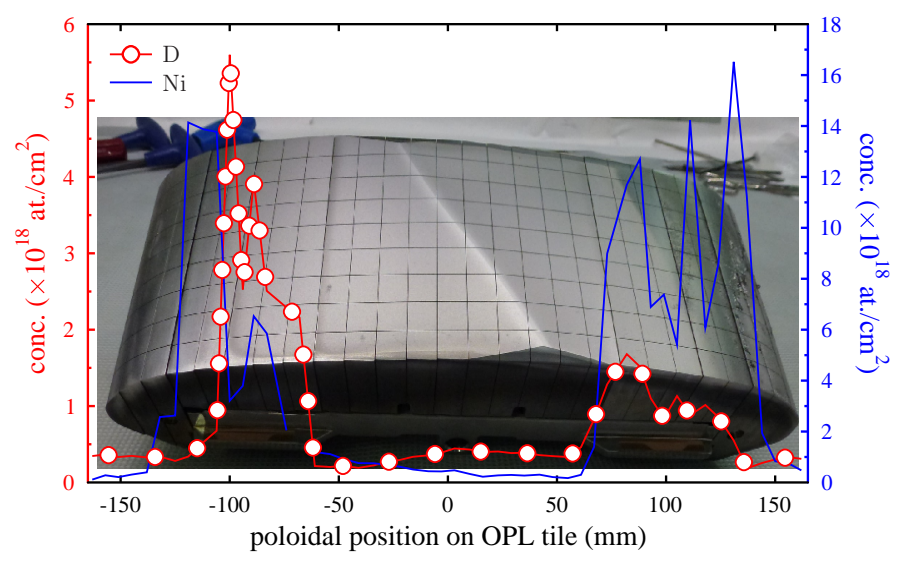

FIG. 1: (Color online) Deuterium toroidal distribution on the mid-plane OPL tile as obtained with NRA measurements. Also shown the Ni marker interlayer results: low Ni concentration values correlate with thinning or erosion of the OPL tile surface. The centre part region $(-60 \mathrm{~mm} \ldots+60 \mathrm{~mm})$ of the OPL is the eroded zone and has the lowest $\mathrm{D}$ concentration values of $\sim 3.3 \times 10^{17} \mathrm{at} . / \mathrm{cm}^{2}$.

calibration standard and a constant value for nuclear reaction cross-section provides a mean value of $3.45 \times 10^{17}$ at. $/ \mathrm{cm}^{2}$. The factor of $\sim 2.37$ difference arises from the use of a non-varying value for cross-section. This correction factor $f=2.37$ will be used later in Sect. III A 3 where the NRA results of the IWGL tiles are calibrated using only the D reference sample and the single value for reaction cross-section.

The lower region OPL tile analysis results to an averaged D retention value of $2.03 \times 10^{18}$ at./ $\mathrm{cm}^{2}$ by using NRA calibration sample and the aforementioned correction factor. Taking into account the OPL tile surface area, the global D retention values can be obtained for the mid-plane and the lower region tile rows as $4.13 \times 10^{21}$ and $1.02 \times 10^{22} \mathrm{D}$ atoms, respectively. Averaging these values and integrating over the whole OPL gives a global outer wall limiter retention value of $1.65 \times 10^{23} \mathrm{D}$ atoms.

\section{Inner Wall Guard Limiters}

IWGL tiles used in the present study were removed from the upper region, mid-plane and lower region of the inner wall (identification 2XR19, 2XR10 and 2XR3, respectively). As was with the OPL tiles, the IBA analysis for IWGL tiles were done in the toroidal direction of the tiles. However, the results are calibrated by using the D reference sample (see Sect.Sect. II) and 


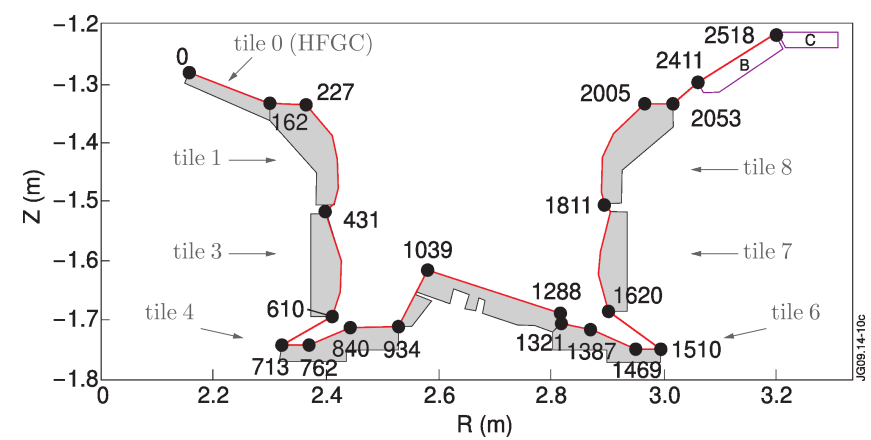

FIG. 2: (Color online) The divertor S coordinates showing poloidal trajectory following the tile surfaces. The tile 1 apron is between S coordinates $162 \mathrm{~mm}$ and $227 \mathrm{~mm}$.

corrected with the factor presented in Sect. Sect. III A 2.

From the IBA results it is evident that the D retention has its minima at the erosion dominated zone in the central part of the tile. The erosion zone $\mathrm{D}$ retention values for upper, mid-plane and lower IWGL region are $1.9 \times 10^{17}$ at. $/ \mathrm{cm}^{2}, 2.5 \times 10^{16}$ at. $/ \mathrm{cm}^{2}$ and $1.1 \times 10^{17}$ at. $/ \mathrm{cm}^{2}$, respectively. The lowest $\mathrm{D}$ retention is measured at the mid-plane with the highest erosion as previously shown with tile profiling [8]. Presently only the lower IWGL region tile has been analysed with IBA as a whole. Using that result as an approximation for all of the IWGL tiles yields to a total D concentration per one IWGL tile $4.8 \times 10^{17}$ at. $/ \mathrm{cm}^{2}$ or $1.2 \times 10^{20} \mathrm{D}$ atoms. An integration over all the IWGL tiles and limiters in the vessel yields a global $\mathrm{D}$ retention value of $2.3 \times 10^{22}$ atoms.

\section{B. Divertor}

The divertor Tiles 1, 3, 4 and HFGC (Tile 0) were analysed with IBA and SIMS for D and deposition composition. In addition to SIMS also ERDA was used for Tiles 6, 7 and 8 (ERDA details in Ref. [10]). The measurement points form a poloidal distribution along the divertor. For locating the analysis points an $\mathrm{S}$ coordinate system is used and presented in Fig. 2.

The measured total concentration values of retained D in JET-ILW divertor is presented in Fig. 3. The overall $\mathrm{D}$ retention trend implies clearly that most of the retained $\mathrm{D}$ is on the inner divertor. Some variation is observed in the values obtained with different analysis methods. These may be due to toroidal variation of $\mathrm{D}$ concentration, surface roughness effects or even microscopically local nonuniform D surface distribution [11]. Averaging the D retention values presented in Fig. 3 and integrating over all the divertor tiles in toroidal direction gives total D concentration 


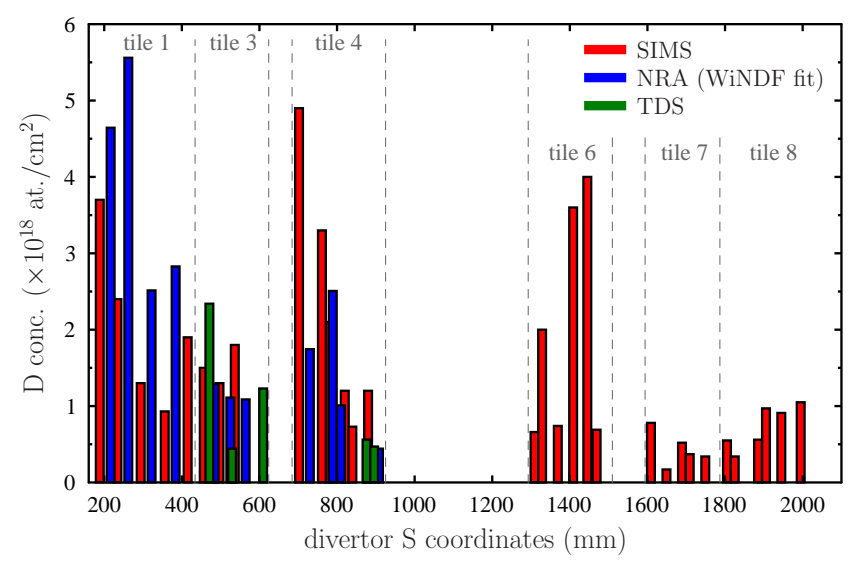

FIG. 3: (Color online) The retained deuterium distribution in the JET-ILW divertor tiles as measured with SIMS, NRA and TDS. The D concentration is presented as a function of S coordinates. The divertor tile positions at corresponding $\mathrm{S}$ coordinates are separated with dashed lines.

TABLE I: Summary of the retained D total concentrations from JET-

ILW 2010 - 2012 campaign.

\begin{tabular}{l|c} 
JET vessel component & concentration (D atoms) \\
\hline \hline Upper Dump Plates & $1.5 \times 10^{22}$ \\
\hline Outer Poloidal Limiters & $1.6 \times 10^{23}$ \\
\hline Inner Wall Guard Limiters & $2.3 \times 10^{22}$ \\
\hline Divertor, total & $2.9 \times 10^{23}$ \\
-inner divertor (incl. Tile 0) & $2.0 \times 10^{23}$ \\
- Tile 0 and Tile 1 & $1.3 \times 10^{23}$ \\
- outer divertor & $8.6 \times 10^{22}$ \\
- Tile 5 & not measured
\end{tabular}

values of $2.0 \times 10^{23}$ and $8.6 \times 10^{22} \mathrm{D}$ atoms for the inner and outer divertor, respectively. Nearly $63 \%$ of the inner divertor D retention takes place on Tile 0 (HFGC) and Tile 1. This correlates with the fact that most of the deposition was measured from that region. Fig. 4 presents the qualitative and quantitative information of the inner divertor depositited layers. A more detailed analysis of the multilayered deposition structure is in Ref. [9]. Most of the $\mathrm{Be}$ and $\mathrm{O}$ is on Tile 0 and Tile 


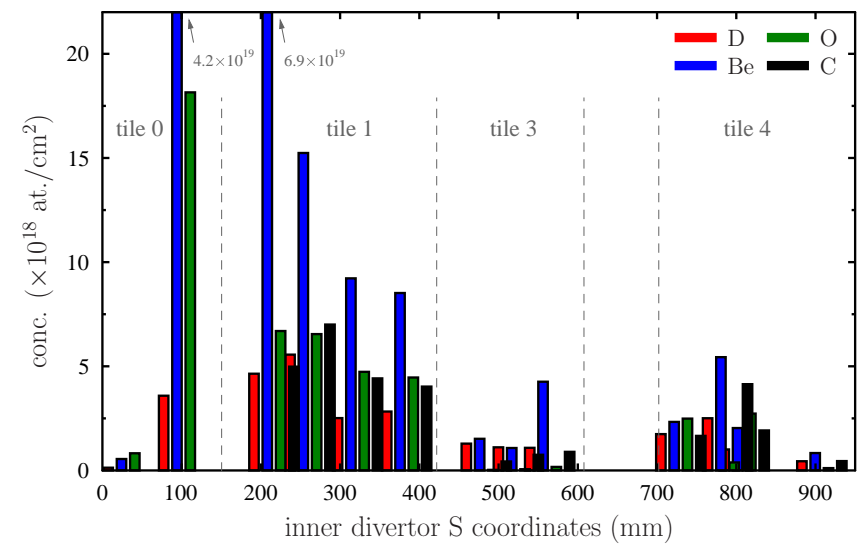

FIG. 4: (Color online) The $\mathrm{D}, \mathrm{Be}, \mathrm{C}$ and $\mathrm{O}$ distribution in the JET-ILW inner divertor tiles as a function of S coordinate. The concentrations were obtained with NRA and EBS and fitted with WiNDF. Most of the deposition takes place on the plasma wetted region on tile $0(\mathrm{~S}$ coordinates $60 \ldots 160 \mathrm{~mm})$ and on the apron of tile $1(162 \ldots 230 \mathrm{~mm})$, where also most of the $\mathrm{D}$ co-deposition takes place $\sim 5 \times 10^{18}$ at. $/ \mathrm{cm}^{2}$. The plasma shadowed region on tile $0(<60 \mathrm{~mm})$ show concentrations for D: $1.3 \times 10^{17} \mathrm{at} . / \mathrm{cm}^{2}$, Be: $6 \times 10^{17}$ at. $/ \mathrm{cm}^{2}$ and O: $0.8 \times 10^{17}$ at. $/ \mathrm{cm}^{2}$, which are similar as obtained for tile 4 shadowed region (>900 mm).

1 , but $\mathrm{C}$ is present only on Tile 3 and onwards. From the divertor results it is not unambiguous whether the D retention is composition dependent of the deposited layer. Some correlation of $\mathrm{D}$ retention is with the thickness of the deposited layer on the inner divertor. The outer divertor deposited layers do not vary as much as the layers on the inner divertor. The D retention is seen mostly on the (Fig. 5 sloping part on Tile 6).

The divertor remote areas had installed passive diagnostic Louvre Clips (LC) for monitoring deposition on the cold regions in the inner and outer divertor (remote areas between Tile 3 and 4 and Tile 6 and 7, Fig. 2). The amount of retained D on the inner and outer LC was $(3.0 \pm 1.7) \times 10^{18}$ at. $/ \mathrm{cm}^{2}$ and $(1.9 \pm 0.8) \times 10^{18}$ at. $/ \mathrm{cm}^{2}$, respectively. The relative concentration of $\mathrm{D} /(\mathrm{Be}+\mathrm{O}+\mathrm{C})$ was $(0.49 \pm 0.22)$ on the inner LC and $(0.36 \pm 0.07)$ on the outer LC. This result shows that there is more $\mathrm{D}$ migrating to the inner remote areas. For comparison, Tile 1 concentration ratio is $(0.22 \pm 0.11)$ without any $\mathrm{C}$ on the tile, Tile $3(0.48 \pm 0.24)$ with miniscular amounts of $\mathrm{O}$ and Tile $4(0.27 \pm 0.03)$ with nearly $1: 1 \mathrm{Be}: \mathrm{C}$ ratio.

The TDS spectra were calibrated with an identical D implanted polycrystalline $\mathrm{W}$ sample that was used for calibrating the NRA and SIMS results. TDS was performed in the present work only 


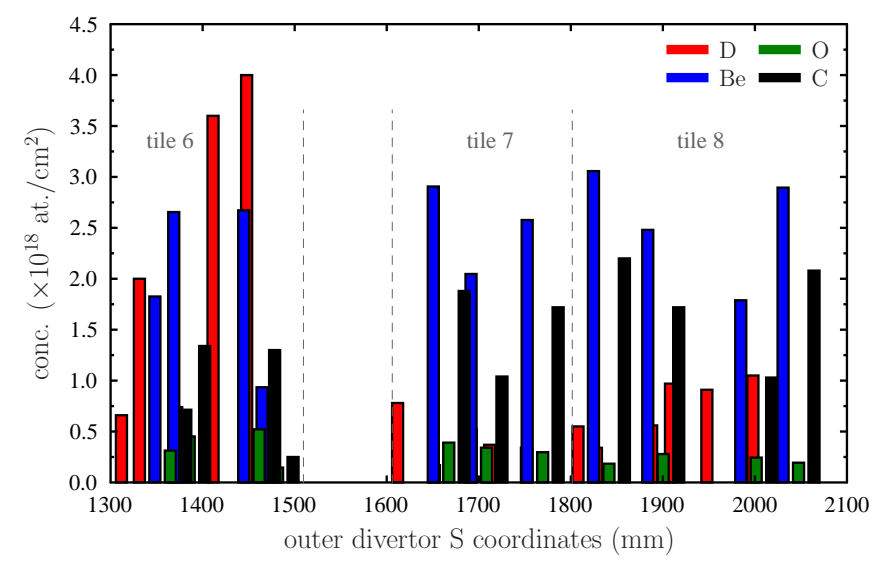

FIG. 5: (Color online) The $\mathrm{D}, \mathrm{Be}, \mathrm{C}$ and $\mathrm{O}$ poloidal distribution in the JET-ILW outer divertor tiles as a function of S coordinate. The D concentrations were obtained with SIMS and the Be, C and O impurities with ERDA (see Ref.[10]). The highest D concentration $\left(\sim 3.75 \times 10^{18} \mathrm{at} . / \mathrm{cm}^{2}\right)$ is on the sloping part of tile 6 ( $\mathrm{S}$ coordinates $1390 \ldots 1470 \mathrm{~mm}$ ). Be, $\mathrm{C}$ and $\mathrm{O}$ do not show massive concentration variations in the deposits.

for selected samples representing Tile 3 and Tile 4. The integrated D concetration values from TDS are presented in Fig. 3. The Tile $4 \mathrm{D}$ concentration results are somewhat lower than obtained with other analyses methods. This is probably due to the fact that the Tile 4 TDS samples were cored from the vicinity of the plasma-shadowed region. In addition to the $1 \mathrm{~mm}$ thick sample of the W-coated surface, a bulk CFC sample was prepared from Tile 4. The sample depth of this sample corresponds to $1.5 \mathrm{~mm}$ from the tile surface at which the TDS showed a D concentration of $1.0 \times 10^{14}$ at. $/ \mathrm{cm}^{2}$ when annealed to $1000^{\circ} \mathrm{C}$.

The $\mathrm{D}_{2}$ desorption spectra for Tile 3 and Tile 4 samples are fairly broad with the desorption at $\sim 80^{\circ} \mathrm{C}$. Interestingly, the Tile 4 samples showed two clear desorption maxima (first peak at 300 to $320^{\circ} \mathrm{C}$ and second at 460 to $480^{\circ} \mathrm{C}$ ) whereas Tile 3 samples had only one desorption maximum (between 400 to $430^{\circ} \mathrm{C}$ ). This difference is most likely due to the tile coatings: Tile 4 has a W coating, whereas Tile 3 surface coating is Mo. Both of the tiles showed $\mathrm{T}_{2}$ desorption. Some random $\mathrm{T}_{2}$ peaks were recorded at low temperatures, but a clear $\mathrm{T}_{2}$ outgassing took place at high temperatures starting at $\sim 800^{\circ} \mathrm{C}$. The quantification of $\mathrm{T}_{2}$ will be part of a future work. Additionally, at high temperatures $\gtrsim 900^{\circ} \mathrm{C}$ the desorption of Be started. Since bulk Be is having a melting point at $\sim 1200^{\circ} \mathrm{C}$, it is concluded that the observed signal is due to the evaporation of the Be deposits from the tile surface. As the Be desorption takes place at the high end of the 
annealing profile, total quantities were not concluded within this work.

\section{Summary}

Table I summarizes the present results for global D retention of JET-ILW as measured from the first wall components. During the 2010-2012 experimental campaign approximately $1.67 \times 10^{26}$ D atoms were puffed into JET [12]. The post-mortem analyses of the present work map the distribution of the $4.88 \times 10^{23}$ retained $\mathrm{D}$ atoms, which corresponds to $0.3 \%$ or $1.6 \mathrm{~g}$ of retained $\mathrm{D}$. This results to a global retention rate of $7.1 \times 10^{18} \mathrm{D} / \mathrm{s}$ when normalised to $6.8 \times 10^{4}$ s operational time of the 2010-2012 JET-ILW campaign. The obtained D retention values can be considered as upper limit of retention since no cleaning pulses were performed in the 2010-2012 period.

The main chamber erosion zones do not show high retention values for D. Trapped D is mostly in main chamber regions with less plasma-surface interactions. These areas have small and varying amounts of Be deposits but no significant concentrations of $\mathrm{C}$ or $\mathrm{O}$ [9]. Nearly $60 \%$ of the retained $\mathrm{D}$ is on the divertor and the rest is trapped in the main chamber. Most of the eroded material from the main chamber end up to the upper region of the inner divertor, where the highest $\mathrm{D}$ retention values are also measured. However, high $\mathrm{D}$ retention values were also obtained from shadowed region of Tile 4 with comparably low values for deposited impurities.

\section{Acknowledgments}

This work, supported by the European Communities under the contract of Association between Euratom-Tekes, was carried out within the framework of the European Fusion Development Agreement (EFDA). The views and opinions expressed herein do not necessarily reflect those of the European Commission.

[1] G. F. Matthews, P. Edwards, T. Hirai, M. Kear, A. Lioure, P. Lomas, A. Loving, C. Lungu, H. Maier, P. Mertens, et al., Phys. Scripta T128, 137 (2007).

[2] S. Brezinsek, T. Loarer, V. Philipps, H. Esser, S. GrÃijnhagen, R. Smith, R. Felton, J. Banks, P. Belo, A. Boboc, et al., nf 53, 083023 (2013). 
[3] J. P. Coad, E. Alves, N. P. Barradas, A. Baron-Wiechec, N. Catarino, K. Heinola, J. Likonen, M. Mayer, G. F. Matthews, P. Petersson, et al., ps 2014, 014012 (2014).

[4] A. Widdowson, E. Alves, C. F. Ayres, A. Baron-Wiechec, S. Brezinsek, N. Catarino, J. P. Coad, K. Heinola, J. Likonen, G. F. Matthews, et al., Phys. Scripta 2014, 014010 (2014).

[5] J. Likonen, E. Alves, A. Baron-Wiechec, S. Brezinsek, J. P. Coad, A. Hakola, K. Heinola, S. Koivuranta, G. F. Matthews, P. Petersson, et al., Phys. Scripta 2014, 014016 (2014).

[6] N. P. Barradas and C. Jeynes, Nucl. Instr. Meth. Phys. Res. B 266, 1875 (2008).

[7] K. Heinola, T. Ahlgren, E. Vainonen-Ahlgren, J. Likonen, and J. Keinonen, Phys. Scripta T128, 91 (2007).

[8] K. Heinola, C. F. Ayres, A. Baron-Wiechec, J. P. Coad, J. Likonen, G. F. Matthews, A. Widdowson, and J.-E. Contributors, ps 2014, 014013 (2014).

[9] A. Baron-Wiechec, A. Widdowson, E. Alves, C. F. Ayres, N. P. Barradas, S. Brezinsek, J. P. Coad, N. Catarino, K. Heinola, J. Likonen, et al., PSI-21 proceedings (2014).

[10] P. Petersson, H. Bergsåker, I. Bykov, G. Possnert, J. Likonen, J. Linke, S. Koivuranta, A. Widdowson, H. G. Esser, and M. Rubel, PSI-21 proceedings (2014).

[11] H. Bergsåker, P. Petersson, I. Bykov, G. Possnert, J. Likonen, S. Koivuranta, J. P. Coad, W. van Renterghem, I. Uytdenhouven, and A. Widdowson, PSI-21 proceedings (2014).

[12] V. Philipps, private communication (2014). 